\title{
The Transformational Impact of Intense Virtual Teamwork Experiences on Team Member Psychometrics: An Exploratory Study
}

\author{
William Swart \\ East Carolina University \\ Judy A. Siguaw \\ East Carolina University
}

\begin{abstract}
Managers seeking to assure the success of teams in their organizations often resort to the use of psychometric measures to assign individuals to teams. We obtained psychometrics of 13 virtual teams before and after they engaged in five weeks of intense virtual collaborative activities. We found that significant changes in psychometrics had occurred during this period, suggesting that intense virtual teamwork experience themselves may modify individual psychometrics as teams strive to achieve their goals. While exploratory in nature, the statistical results are strong and serve as a cautionary note to all companies that use psychometrics to guide their actions.
\end{abstract}

Keywords: human resources, project management, human performance, virtual teams, psychometrics

\section{INTRODUCTION}

Effective teams are critical to business success. Hoch (2014) and Deloitte (2016) note that organizations are restructuring to enable the more efficacious use of evolving teams to meet the challenges faced in today's uncertain, dynamic, complex, and hyper-competitive business environment. Moreover, technological advances have increased the utilization of virtual teams, which have evolved into the dominant organizational team structure for global businesses (Gilson, Maynard, Young, Vartiainen, \& Hakonen, 2014; Greenberg, Greenberg, \& Antonucci, 2007; Zuofa \& Ochieng, 2017). Indeed, in response to a biennial global survey, $89 \%$ of 1,620 executives of major organizations across 90 countries reported working on one or more virtual teams (CultureWizard, 2018).

Teams are defined as a "set of interdependent individuals bound by a collective aim" (Glassop, 2002, p. 226). For the last three decades, academic researchers have documented the benefits of organizational teams. For example, the empirical work of Glassop (2002) indicated that there is a significant increase in productivity, a flatter managerial structure, and a decrease in employee turnover when self-managing teams are utilized within the organization. Allen and Hecht (2004) concluded that members of teams reap greater job satisfaction and confidence. Additionally, Delarue, Van Hootegem, Procter, and Burridge (2008) confirmed that teamwork yields greater organizational performance, and an increase in the positive attitudes and behaviors of employees.

To achieve the utmost in organizational and employee benefits that can accrue through teamwork, some academics and practitioners suggest contemplating the psychometrics of employees during the 
team formation process to find the advantageous mix (e.g., Akmal, 2015; Allen \& Woodley, 2016; Shalwani, Line, Delvinne, Saseendras, \& Sullivan, 2019). The underlying supposition is that team member psychometrics will govern behaviors exhibited and communication flow within the team (Juhász, 2010). In accord, Harper (2018, p. 9) summarizes:

"In an ideal world, your team would have a few strongly extroverted employees to lead the task, a considerable number of agreeable employees to cooperate on decisions and reduce conflict, a considerable number of conscientious individuals to produce highquality work, some emotionally stable employees to remain calm under stressful and pressured environments, and finally, a few employees who are extremely open to experience to input creativity and imaginative ideas."

The more common psychometrics used for team building purposes are personality traits (PT), locus of control (LOC), and emotional intelligence (EI). Prior work offers support for considering PT when forming teams to ensure cohesion and better performance (e.g., Aeron and Pathak, 2012; Guchait, Hamilton, and Hua, 2014; van Vianen and De Dreu 2001). LOC has also been shown to be a factor when forming teams with external vs. internal LOC affecting leadership and followership abilities (Boone, Van Olfen, \& Witteloostuijn, 2005; Nowicki, 2016). Finally, the EI literature encompasses a large body of work (e.g., Hess, \& Bacigalupo, 2011) and a select number of these studies have investigated emotional intelligence and its influence on team effectiveness (e.g., Akila \& Thangavel, 2013; Koman \& Wolff, 2008; Shalwani, Smithwick, Hurtado, \& Sullivan, 2018).

The results of such studies have informed the conventional wisdom for team formation, which suggests using current psychometric properties of potential team members as a means of facilitating more efficacious and cooperative behaviors within the team. However, years of comments from our online MBA students, who are generally juggling full-time work, families, and course work, have described a personal psychometric transformational outcome that occurs as the result of intense virtual teaming experiences. Indeed, based on the qualitative pre- and post-data of $300 \mathrm{MBA}$ students over the last year, more than $50 \%$ were found to have changed personality traits from the beginning to the end of a course which required a demanding team collaboration. In other words, rather than the initial individual psychometric properties transmuting the team traits, the intense team collaborations appear to have transmogrified the individual and overall team psychometric characteristics. While we found these transformations interesting, the qualitative nature of the data limited our analyses. Yet, the meaning of such changes is so intriguing that we were prompted to empirically explore this phenomenon.

In this study, then, we examine a contrarian perspective, proposing that, within an intense virtual collaboration effort, team engagement molds individual psychometrics so that they converge toward a balance dictated by how much of each the individual desires with how much the rest of the members are willing to allow in the pursuit of a common goal. Thus, we question whether it is worthwhile for management to focus on personality traits when forming teams. This research offers several contributions by examining: (1) whether quantitative measures of individual psychometric properties change as the result of short-term, intense virtual teaming experiences, (2) whether changes in individual psychometric properties yield improved individual performance, and (3) whether changes in team psychometric properties improve team performance. The findings offer organizations guidance on team formation, which may save both time and effort for the organizers.

In the following sections, we discuss the relevant literature and present our hypotheses. We then describe the nature of the intense virtual collaboration to which our graduate students are subject, as well as the structure of their collaborative activities which, we believe, mimics teamwork in knowledge-based industries. We then provide the study methodology and present our results. We close by offering a discussion of the results, our conclusions, limitations of the study, and suggestions for future research. 


\section{THEORETICAL UNDERPINNING}

The underpinning for our study is founded on Bandura's (1977) Efficacy Theory. Bandura (1977, p. 191) suggested that "cognitive processes mediate change but that cognitive events are induced and altered most readily by experience of mastery arising from effective performance." Bandura's theory was originally developed to assist individuals facing events or situations generating dysfunctional anxiety or fear. Bandura's theory combined outcome expectancy, referencing the conviction that certain behaviors will lead to specific outcomes, with efficacy expectation, the belief that a specific behavior can be successfully performed in order to reach the desired outcome. Bandura's theory is fitting for research exploring how personalities may be intentionally altered as a means of achieving specific goals.

\section{LITERATURE REVIEW \& HYPOTHESES DEVELOPMENT}

\section{Personality Traits}

Following the path forged by Tupes and Christal (1961), Goldberg (1990) proposes the five-factor model of personality--Extraversion, Agreeableness, Conscientiousness, Neuroticism, and Openness to Experience. Google Scholar indicates that the "Big Five" model has been cited in academic publications thousands of times. However, more recent work suggests there are six primary factors (e.g., Ashton, Lee, \& Goldberg, 2004). Consequently, Lee and Ashton (2004) use Goldberg's five-factor model as a jumping off point to develop the HEXACO Personality Inventory. Over time, this inventory is revised and retitled as the HEXACO Personality Inventory-Revised (HEXACO-PI-R). This scale assesses the following six factors: honesty-humility, extraversion, conscientiousness, openness to experience, agreeableness, and emotionality (Ashton \& Lee, 2009). The HEXACO-PI-R has been used extensively in the last decade to measure individual personalities (including Bowes, Watts, Thompson, \& Lilienfeld, 2019, and Kaufman, Yaden, Hyde, \& Tsukayama, 2019, among at least 50 other publications). However, few of these investigations involve the impact of team personality on team effectiveness. An exception is Vasilatos (2010) who reports team performance improves with higher mean scores on agreeableness, extraversion, and honesty-humility for face-to-face (FTF) teams, as opposed to higher mean levels of extraversion, emotionality, openness to experience, and honesty-humility for virtual teams. Conscientiousness was inversely related to effectiveness for virtual teams.

As previously noted, PT are generally perceived to affect team effectiveness. For example, van Vianen and De Dreu (2001) find that low levels of conscientiousness and agreeableness positively influence task cohesion and team performance, while high levels of extraversion and emotional stability positively affect social cohesion. The work of Guchait, Hamilton, and Hua (2014) reveals that composite team conscientiousness is positively associated with taskwork understanding and transactive memory systems in the early stages of team formation, and team agreeableness is positively correlated with taskwork understanding and transactive memory systems in the later stages of the team's life span. Additionally, Wang and Hsu (2012) indicate that teams with higher levels of conscientiousness and extraversion and lower levels of neuroticism perform better on tasks. Relatedly, Aeron and Pathak (2012) find positive effects of agreeableness and extraversion, and negative effects of neuroticism, on team cohesion but do not surface a relationship between cohesion and conscientiousness.

In the past, an individual's personality was considered quite stable, but in recent times, personality has been judged to be malleable (e.g., Lucas \& Donnellan, 2011; Specht, Egloff, \& Schmukle, 2011). Tasselli, Kilduff, and Landis (2018, p. 468) define personality transformation as a "change in the individual's characteristic pattern of thought, emotion, or behavior as well as change to the mechanisms behind these patterns." Existential and humanistic theories propose that individuals choose to overcome a lack of meaning in their lives by developing positive personality attributes in order to achieve fulfilment (Deci \& Ryan 1985, 2000; Hounkpatin, Wood, Boyce, \& Dunn, 2015; Joseph \& Linley 2005), while the social investment perspective suggests that personality is altered in order to adapt to the roles defined by marriage and work (Roberts \& Wood 2006; Roberts, Wood, \& Smith, 2005). Following the latter view, others have examined the impact of events on personality. In their research, Anusic and Schimmack 
(2016, p. 774) find evidence that "individual life events may have rather small effects on personality but, taken together, changing circumstances can contribute to changes in personality." In accord with this finding, Jackson, Thoemmes, Jonkmann, Lüdtke, and Trautwe's (2012) longitudinal study indicates that military training changes individual personality characteristics and that the changes are sustained even five years later after the enlistees have entered college or the civilian workforce. The results of these studies also have support from others (e.g., Bleidorn 2012; Martin, 2013; Zimmermann \& Neyer 2013).

While most studies have examined changes to individual personality, Tasa, Sears, and Schat (2011) report that collective efficacy, or group confidence, elicits or suppresses behaviors stemming from personality characteristics. In their conceptual paper, Roberge and Huang (2019) argue that certain individual traits, such as extraversion, conscientiousness, and openness to experiences, may imbue the group with these personality traits and causing these characteristics to become dominant group traits. Moreover, Roberge and Huang (2019) also suggest that the personalities of individuals and group members will change to adapt to the task to be performed by the team. That is, if it is a social task, the team and its members present greater levels of agreeableness, extraversion, and altruism, while under cognitive task conditions, the individuals and the team reveal greater degrees of conscientiousness and openness to experiences.

\section{Locus of Control}

Locus of control (LOC) was first explored by Rotter (1954; 1966), who conceptualized the psychological construct as a continuum with internal and external endpoints. According to Rotter (1966), individuals with an internal LOC believe that they can influence the outcome of events and attribute their successes or failures to their own actions and abilities. On the other hand, individuals with an external LOC believe that life outcomes are beyond their control and they attribute their successes or failures to external factors such as fate, luck, or other people. Nowicki (2016) proposes, while internality is generally considered a more desirable trait, both internality and externality have advantages and disadvantages. Research on LOC indicates that individuals with a high internal locus of control make better leaders while those with high external locus of control make better followers (Nowicki, 2016). Relatedly, Boone et al, (2005) found that teams with high average internal locus of control performed better without leaders, while teams with high average external locus of control perform better with leaders.

LOC is determined at an early age by how parents raise a child. However, it can be modified through deliberate activities (Nowicki, 2016). Moreover, recent studies in neuroscience posit that the adult brain is somewhat malleable, providing individuals with the ability to alter their electrical brain activity and, in turn, their behavior (Waldman, Balthazard, and Peterson, 2011), indicating that perhaps LOC can be altered through training. The point of modifying LOC is to achieve the appropriate balance between the internality and externality. This balance is best described by the serenity prayer "god, grant me the serenity to accept things I cannot change, the courage to change those I can, and the wisdom to know the difference."

While Gochenaur (2010) finds that leadership training had no effect on LOC, Stover (1988) demonstrates that leadership training methods do increase participants' internal LOC score. Similarly, Weissbein, Huang, Ford, and Schmidt (2011) successfully use a pre-training intervention to intentionally influence LOC, so that success is attributed to effort and strategy, which in turn affects the motivation to learn. Problem-based learning methods are effectually used to develop internal LOC among nursing students (Günüşen, Serçekus, \& Edeer, 2014), while mentoring programs increase student internal LOC (Demir, Demir, Bulut, \& Hisar, 2014). Despite acknowledging that little is known about how changes in LOC affect performance, Ottley, Crouse, Ziemkiewicz, and Chang (2012) report that altering study participants' LOC through priming scenarios results in predictable changes in performance.

\section{Emotional Intelligence}

Emotional intelligence (EI) is the ability to recognize, understand, and manage emotions in ourselves and others, and consists of four "quadrants": Self-Awareness, Social Awareness, Self-Management, and Relationship Management (Goleman, Boyatzis, \& McKee, 2002). For example, the EI of leaders impacts 
the emotional intelligence of teams (Goleman et al., 2002). EI predicts the team task orientation and the team maintenance of self-managed teams (Frye, Bennett, \& Caldwell, 2006), and facilitates better individual and group decisions (Hess \& Bacigalupo, 2011), as well as improves individual and team performance (Shalwani et al., 2019; Shalwani, et al., 2018). Coetzer (2015) finds that EI is a more significant predictor of efficacy for teamwork than cognitive intelligence.

Chemiss and Adler (2000) note that, although people do not inherently possess Goleman's five dimensions of emotional intelligence, EI can be learned, although such an effort is not easy or linear. A number of studies indicate the effectiveness of EI training for children, adolescents, college students, and nurses (e.g., Codier, Freitas \& Muneno, 2013; Motamedi, Ghobari-Bonab, Beh-pajooh, Yekta, \& Afrooz, 2017; Orak, Farahani, Kelishami, Seyedfatemi, Banihashemi, \& Havaei, 2016; Ulutas \& Ömeroglu, 2007). More relevant to the study at hand, Clarke (2010) finds that a one-day EI training has no impact on MBA students, but when the training is followed by intensive team-based learning, the EI dimension of relationship management significantly increases.

Many studies promote the development of EI because of the generally accepted belief that improvements in EI will yield better job performance. However, while there is a substantial body of research connecting EI and job performance (e.g., Dhani \& Sharma, 2016; Joseph \& Newman 2010; Joseph, Jin, Newman, and O'Boyle, 2014; O'Boyle, Humphrey, Pollack, Hawver, \& Story, 2011), there is a paucity of research examining how changes in EI affect performance. Nonetheless, we still anticipate that such changes will have a positive effect based on the strong relationship between EI and workplace performance.

\section{Gender Differences}

In this study, we also examine how gender might influence changes in psychometric properties. Gender differences have been previously noted in the constructs of interest in this study. For example, Dhani and Sharma (2017) find that females score higher on EI and job performance; Kaifi and Noori (2010) also indicate that female managers have higher EI. Concerning LOC, women are more likely to exhibit greater externality, which reportedly explains some portion of the gender pay gap and slower upward mobility in the workplace (e.g., Semykina \& Linz, 2010; Yu-Wei \& Linz, 2017). In relation to PT, Costa, Terracciano, and McCrae (2001) suggest that gender differences in personality traits across 26 cultures are very small compared to individual differences within genders, but other studies note some general variances. For example, conscientiousness and openness to experiences are stronger predictors of leadership effectiveness for women, although for men, extraversion is a stronger predictor (Huszczo \& Endres, 2017). Laher and Croxford (2013) find significant gender differences in multiple traits, including neuroticism, anxiety, vulnerability, depression, self-consciousness, extraversion, warmth, activity, assertiveness, positive emotions, aesthetics, feelings, ideas, agreeableness, compliance, tendermindedness, altruism, modesty, straightforwardness, trust, conscientiousness, order, achievement striving and self-discipline among university students; they posit that such differences are systematic and innate.

\section{RESEARCH HYPOTHESES}

As indicated earlier in this paper, $89 \%$ of 1,620 executives of major organizations across 90 countries reported working on one or more virtual teams (CultureWizard, 2018). Yet, based on the results of our literature survey, very little is known about the impact of individual and team personality traits on the performance of virtual teams and even less is known about the effects of virtual teamwork on individual and team personality traits. Thus, our research hypotheses are that short term, intense, virtual teaming experiences will:

H1: Moderate extreme individual personality traits (Personality type, Locus of Control\& Emotional Intelligence).

H2: Induce statistically significant changes in individual psychometrics. 
H3: Induce changes in psychometrics that differ by gender.

H4: Induce changes in personality traits that are unique and significant predictors of individual performance.

H5: Induce changes in team personality traits (Personality type, Locus of Control, \& Emotional Intelligence).

H6: Induce changes in personality traits that are unique and significant predictors of team performance.

\section{METHODS}

As mentioned previously, the study reported in this paper builds upon the results obtained from preand post-course data collected from 300 MBA students over a year's period. An analysis of the personality traits derived using the16personalities (available at www.16personalities.com) and Rotter's LOC (1966; available at http://www.psych.uncc.edu/pagoolka/LC.html) scales leaves little doubt, as shown in Table 1, that both personality traits and locus of control changed with surprising frequency from the beginning to the end of the course. While we found these transformations interesting, the qualitative nature of the personality trait data reduced our ability to subject the data to in-depth analyses. We thus followed up by designing this study to further explore the nature of the changes we had observed.

TABLE 1

PT \& LOC CHANGES DURING INTENSE COLLABORATION

\begin{tabular}{|l|c|c|c|}
\cline { 2 - 4 } \multicolumn{1}{c|}{} & \multicolumn{2}{c|}{ online } & f2f \\
\cline { 2 - 4 } \%Change in & regular sem. & summer & regular sem \\
\hline PTI & $53 \%$ & $41 \%$ & $54 \%$ \\
\hline LOC & $75 \%$ & $67 \%$ & $66 \%$ \\
\hline PTI \& LOC & $43 \%$ & $29 \%$ & $46 \%$ \\
\hline N & 159 & 106 & 35 \\
\hline
\end{tabular}

\section{Participants}

The participants in this study were Master's in Business Administration (MBA) students enrolled in a required business analytics class. Our MBA program has a current enrollment of 806 students with 710 who are exclusively online students. The online students are representative of the white-collar work force and are professionals from all walks of life who must juggle jobs, family, and school. Students that are not exclusively online constitute a mix of professionals from the local community as well as full-time students. The latter group of students mixes face-to-face (FTF) and online classes (DE) to complete their program of study.

A total of 58 online students enrolled in the business analytics course during the summer of 2019 participated in this study. Twenty-seven enrollees were male and 31 were female. Forty-six of these students had full time jobs and another five others were employed as graduate assistants in the College of Business. Of those who had full time jobs, there was one CEO, six directors, 18 managers and 21 professionals. The summer semester is condensed into five weeks and, hence, the workload is particularly intense. The 58 students constituted 13 teams. 


\section{Description of Teamwork}

The online business analytics course, like its FTF counterpart, is taught as a flipped class (Swart \& Wuensch, 2016). The class is structured to resemble a knowledge-based industry project. The end-product is to gain business analytics knowledge with the measurable goal being to earn an "A" in the course. The components of the end-product are the 16 modules comprising the content of the business analytics course that, together, form the end product - e.g. knowledge of the course content. Student teams collaborate on gaining each module's knowledge through virtual interactive group learning. The flipped pedagogy consists of students having to view video lectures and reading assignments on their own. Armed with this knowledge, they collaborate as a virtual group on a problem and/or case to apply the knowledge gained in the module and to gain mastery of the material. When the team indicates that they have mastered the subject matter, they take an individual quiz to assess their command of the material. Thus, the completion of each module is a milestone toward achieving the team's final product.

The constant team collaboration required across the term facilitates team identification, joint reliance, and mutual influence, which in turn, enhances team dynamics and team performance (Ashforth, Harrison, \& Corley, 2008; Carson, Tesluk, \& Marrone, 2007). Thus, the course mimics teamwork in knowledgebased industries in that each team member must share knowledge and accept responsibility for success of the project, much like teams in the workplace must do.

\section{Measures}

The constructs of interest in this study are assessed using pre-existing scales that are commonplace in the management and psychology literatures. To examine team member personalities, the HEXACO-PI-R instrument is used (http://hexaco.org/hexaco-online; Ashton \& Lee, 2009), while the Rotter locus of control survey is used to measure LOC, http://www.psych.uncc.edu/pagoolka/LC.html; Rotter, 1966). To assess emotional intelligence, the Global Emotional Intelligence Test (GEIT) is used (https://globalleadershipfoundation.com/geit/eitest.htm120131212). These surveys were administered to all participating students at the beginning of the summer term (pre-course) and again at the end of the summer term (post-course). Individual performance is measured by the individual grade received on the last exam of the semester; team performance is evaluated by the average team grade on the last exam.

\section{ANALYSIS AND RESULTS}

\section{Testing H1 - Intense Virtual Teamwork Moderates Extreme Personality Traits}

We compiled the beginning and end-of-term responses from our students to the psychometric instruments used and noted how many show an increase, how many a decrease, and how many stay the same on each psychometric measure. The results are presented in Table 2 . Between $60 \%$ and $95 \%$ of the participants changed their score on various domains of the HEXACO-PI-R survey. Between $64 \%$ and $78 \%$ changed their domain scores on the GEIT emotional intelligence survey, and $72 \%$ changed their locus of control. Thus, many participants changed their psychometric scores after the intense virtual teaming experience. An intriguing aspect of the results shown in Table 2 is that there are a substantial number of students scoring lower, as well as higher, on each psychometric by the end of the class. 
TABLE 2

\section{PSYCHOMETRIC SCORE SHIFT PATTERNS FROM} BEGINNING TO END OF COURSE

\begin{tabular}{|c|c|c|c|c|}
\hline \multirow[t]{2}{*}{ HEXACO-PI-R DOMAIN LEVEL SCORES } & \multicolumn{3}{|c|}{ End Scores (compared to beginning scores) } & \multirow{2}{*}{$\begin{array}{c}\text { \% students } \\
\text { changing }\end{array}$} \\
\hline & Lower & No Change & Higher & \\
\hline DOMAIN & & & & psychometric \\
\hline Honesty - Humility & 31 & 6 & 21 & $90 \%$ \\
\hline Emotionality & 23 & 3 & 32 & $95 \%$ \\
\hline Extraversion & 17 & 9 & 32 & $84 \%$ \\
\hline Agreeableness & 22 & 5 & 31 & $91 \%$ \\
\hline Conscientiousness & 26 & 7 & 25 & $88 \%$ \\
\hline Openess to Experience & 19 & 6 & 33 & $90 \%$ \\
\hline Altruism & 25 & 23 & 10 & $60 \%$ \\
\hline \multicolumn{5}{|c|}{ GLOBAL EMOTIONAL INTELLIGENCE SCORES } \\
\hline \multicolumn{5}{|l|}{ QUADRANT } \\
\hline Self-Awareness & 24 & 21 & 13 & $64 \%$ \\
\hline Self-Management & 24 & 13 & 21 & $78 \%$ \\
\hline Social Awareness & 23 & 21 & 14 & $64 \%$ \\
\hline Relationship Management & 28 & 14 & 16 & $76 \%$ \\
\hline LOCUS OF CONTROL & 22 & 16 & 20 & $72 \%$ \\
\hline
\end{tabular}

To investigate the predictive nature of the changes in psychometrics, we arbitrarily select the HEXACO-PI-R domain Honesty-Humility as a test case. We performed a simple regression with End Score being the dependent variable and Begin Score being the independent variable. Thus, the regression model is: End Score $=\beta_{0}+\beta_{1} *$ Begin Score

Table 3 shows the SPSS 26 regression output for the above model. The regression equation explains $70.6 \%$ of the variability in the data. This is represented by Figure 1, which is the graph of actual values obtained from the surveys and the predicted values from the regression equation. 
TABLE 3

REGRESSION OUTPUT FOR HONESTY-HUMILITY

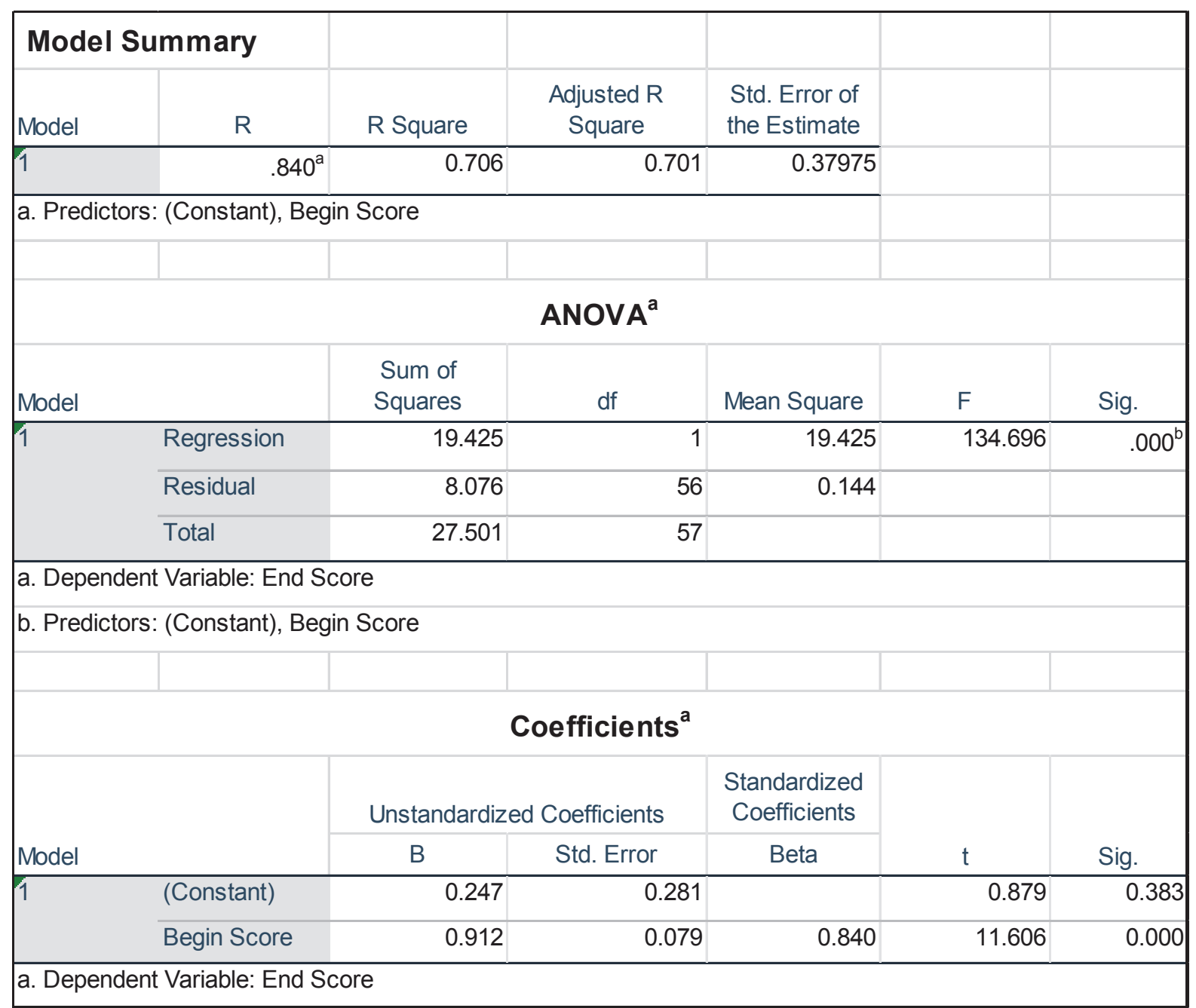

The range of values for the HEXACO-PI-R scores is from 1-5. An examination of the results in Table 3 indicates that the regression coefficient for the independent variable Begin Score is 0.912 with $(p<0.001)$. The implication is that as the Begin Score changes by 1 unit, the dependent variable End Score changes by 0.912 units, implying that there is a "crossover point" when the forecast changes from underpredicting to overpredicting the actual value of the End Score. To examine this possibility, consider Figure 2. Initially, the regression model is predicting lower-ending scores compared to beginning scores. However, at the crossover point, the regression model is predicting higher scores than the beginning scores. The implication is that students who start with low individual scores will have higher scores at the end of the course, while students who have high scores at the beginning of the course will have lower scores at the end of the course. The point at which the forecast switches from lower than initial to higher than initial is what we refer to as the crossover point. Thus, we assert that the impact of experiencing an intense virtual collaboration is to moderate the Honest-Humility scores away from the extremes.

We verified the above phenomenon by counting the number of incidences in our sample of 58 students. We found that 31 had a lower ending score for Honesty-Humility, six had the same score, and 21 had a higher ending score. These results prompted us to examine whether the other psychometrics exhibited similar crossover points. The findings are exhibited in Table 4. As can be noted, all the psychometrics have crossover points. However, not all are in the response ranges. For example, the 
HEXACO-PI-R domain "Openness to Experience" has a crossover point outside of the upper range of 5, while "Altruism" has a crossover point below the minimum range point of 1 . LOC similarly has a crossover range outside its lower range limit of 1. These results support $\mathrm{H} 1$ except for the Altruism domain in the HEXACO-PI-R scale and LOC. There indeed appears to be a moderating influence for extreme values of most psychometrics as a result of the intense short-term virtual collaboration experience.

TABLE 4

\section{REGRESSION RESULTS FOR THE PSYCHOMETRICS AND CORRESPONDING CROSSOVER POINTS}

\begin{tabular}{|c|c|c|c|c|c|c|}
\hline \multirow[t]{2}{*}{ HEXACO-PI-R DOMAIN LEVELS } & & & & & Beginning & \\
\hline & & & & & of Course & Crossover \\
\hline End of Course & Adjusted $\mathbf{R}^{2}$ & Std. Error & $\mathbf{F}$ & Constant & B & Points \\
\hline Honesty - Humility & 0.706 & 0.38 & $134.67^{* * *}$ & 0.247 . & $.912^{* * *}$ & 2.807 \\
\hline Emotionality & 0.759 & 0.378 & $180.09 * * *$ & 0.285 . & $.921 * * *$ & 3.608 \\
\hline Extraversion & 0.769 & 0.33 & $190.78^{* * *}$ & 0.194 . & $.958^{* * *}$ & 4.619 \\
\hline Agreeableness & 0.701 & 0.353 & $134.724 * * *$ & 0.046 . & $.977 * * *$ & 2.000 \\
\hline Conscientiousness & 0.787 & 0.203 & $211.266^{* * *}$ & $.739 * *$ & $.816^{* * *}$ & 4.016 \\
\hline Openess to Experience & 0.831 & 0.317 & $282.175^{* * *}$ & 0.205 . & $.971 * * *$ & 7.069 \\
\hline Altruism & 0.707 & 0.313 & $138.42 * * *$ & 0.034 . & $.962 * * *$ & 0.895 \\
\hline \multicolumn{7}{|c|}{ GLOBAL EMOTIONAL INTELLIGENCE QUADRANTS } \\
\hline \multicolumn{7}{|l|}{ End of Course } \\
\hline Self-Awareness & 0.42 & 1.098 & $42.262 * * *$ & $1.502 *$ & $.707^{* * *}$ & 5.126 \\
\hline Self-Management & 0.317 & 1.458 & $27.509 * * *$ & $2.404 *$ & $.683^{* * *}$ & 7.584 \\
\hline Social Awareness & 0.351 & 1.2 & $30.341^{* * *}$ & $2.676^{*}$ & $.654 * * *$ & 7.734 \\
\hline Relationship Management & 0.304 & 1.535 & $25.914 * * *$ & $2.00 *$ & $.679 * * *$ & 6.231 \\
\hline LOCUS OF CONTROL & 0.503 & 1.518 & $57.575 * * *$ & -0.001 & $1.013 * * *$ & 0.077 \\
\hline$* * * P<0.005 ; * * P<0.05$ & & & & & & \\
\hline
\end{tabular}

\section{Testing H2 - Intense Virtual Teamwork Induces Statistically Significant Psychometric Changes}

While the data establishes that psychometrics can moderate as a result of short-term, intensive virtual teaming experiences, the question remains as to whether the changes between beginning and ending scores are large enough to be statistically significant. To explore this question, we analyzed the distribution of the differences in beginning and ending psychometric scores. First, we tested the individual distributions to determine if they were Gaussian (e.g. normal). The supposition that the data come from a Gaussian distribution was applied to all psychometrics and the results indicate that the supposition cannot be rejected for the following three HEXACO-PI-R domains: honesty-humility, emotionality, and conscientiousness. The supposition is rejected for all other psychometric scores.

To determine which, if any, psychometric scores experienced a statistically significant change SPSS 26 was used to conduct a one sample t-test to the changes in psychometrics we found to follow a Gaussian distribution and we applied a one sample Wilcoxon Signed Rank Test to psychometrics that we found to not be Gaussian. The results, shown in Table 5, indicate that the HEXACO-PI-R domains of "Extraversion" and "Openness to Experience" have a statistically significant increase, while the domain "altruism" has a significant decrease. Thus, H2 is supported only for these domains. H2 is not supported for EI or LOC. 
TABLE 5

ANALYSIS OF THE DIFFERENCE IN PSYCHOMETRIC SCORES DURING THE COURSE

\begin{tabular}{|c|c|c|c|c|c|}
\hline \multicolumn{6}{|c|}{ HEXACO-PI-R DOMAIN LEVEL SCORES } \\
\hline & & & \multicolumn{3}{|c|}{ Significance } \\
\hline DOMAIN & Gaussian & $\mu$ & $\sigma$ & t-test & Wilcoxon \\
\hline$\Delta$ Honesty - Humility & yes & -0.06 & 0.38 & $\mathrm{n}$ & \\
\hline$\Delta$ Emotionality & yes & 0.04 & 0.38 & $\mathrm{n}$ & \\
\hline$\Delta$ Extraversion & no & 0.04 & 0.33 & & $\mathrm{y}^{*}$ \\
\hline$\Delta$ Agreeableness & no & -0.02 & 0.35 & & $\mathrm{n}$ \\
\hline$\Delta$ Conscientiousness & yes & -0.02 & 0.22 & $\mathrm{n}$ & \\
\hline$\Delta$ Openess to Experience & no & 0.11 & 0.31 & & $\mathrm{y}^{*}$ \\
\hline$\Delta$ Altruism & no & -0.13 & 0.31 & & $\mathrm{y}^{* *}$ \\
\hline \multicolumn{6}{|c|}{ GLOBAL EMOTIONAL INTELLIGENCE SCORES } \\
\hline \multicolumn{6}{|l|}{ QUADRANT } \\
\hline$\Delta$ Self-Awareness & no & -0.17 & 1.16 & & $\mathrm{n}$ \\
\hline$\Delta$ Self-Management & no & -0.07 & 1.52 & & $\mathrm{n}$ \\
\hline$\Delta$ Social Awareness & no & -0.05 & 1.28 & & $\mathrm{n}$ \\
\hline$\Delta$ Relationship Management & no & -0.28 & 1.60 & & $\mathrm{n}$ \\
\hline$\triangle$ LOCUS OF CONTROL & no & 0.17 & 1.75 & & $\mathrm{n}$ \\
\hline
\end{tabular}

${ }^{*} p<0.05 ;{ }^{* *} p<0.005$

\section{Testing H3 - Induced Psychometric Changes Vary Significantly by Gender}

We were interested in exploring whether the results exhibited in Table 5 are different based on gender, as reported in our literature survey. To that end, we separated the data by gender and applied the same tests to the data for each gender. Our results are exhibited in Table 6. They indicated that intense, short-term, virtual collaborative experiences in females significantly increased their score on the HEXACO-PI-R domain of openness to experience, while males experienced a statistically significant decrease in the altruism domain. Males also had a marginally significant decrease in the emotional intelligence quadrant of self-awareness $(p=0.051)$. These results partially supported H3. No other significant differences were encountered as a result of the intense short-term collaborative experiences experienced by teams. 
TABLE 6

GENDER DIFFERENCES IN CHANGES TO PSYCHOMETRICS

\begin{tabular}{|c|c|c|c|c|}
\hline \multirow{2}{*}{ HEXACO-PI-R DOMAIN LEVEL SCORES } & & & & \\
\hline & Distribution & \multicolumn{3}{|c|}{ Significance } \\
\hline DOMAIN & Gaussian & Male $(p)$ & Female $(p)$ & $\mathrm{M} / \mathrm{F}$ combined \\
\hline Honesty - Humility & $y$ & no & no & no \\
\hline Emotionality & y & no & no & no \\
\hline Extraversion & $\mathrm{n}$ & no & no & 0.045 \\
\hline Agreeableness & $\mathrm{n}$ & no & no & no \\
\hline Conscientiousness & $y$ & no & no & no \\
\hline Openness to Experience & $\mathrm{n}$ & no & 0.019 & 0.01 \\
\hline Altruism & $\mathrm{n}$ & 0.004 & no & 0.004 \\
\hline $\begin{array}{l}\text { GLOBAL EMOTIONAL INTELLIGENCE } \\
\text { SCORES }\end{array}$ & & & & \\
\hline QUADRANT & & & & \\
\hline Self-Awareness & $\mathrm{n}$ & 0.051 & no & \\
\hline Self-Management & $\mathrm{n}$ & no & no & \\
\hline Social Awareness & $\mathrm{n}$ & no & no & \\
\hline Relationship Management & $\mathrm{n}$ & no & no & \\
\hline LOCUS OF CONTROL & $\mathrm{n}$ & no & no & no \\
\hline $\mathrm{N}$ & & 28 & 30 & 58 \\
\hline
\end{tabular}

Testing H4 - Induced Individual Changes Are Unique and Significant Predictors of Individual Performance

The data in this study represent significant changes in individual psychometrics. To determine whether these psychometric changes have an impact on individual performance, as measured by the exam average, we conducted a stepwise multiple regression whereby the average grade on the exams in the course was the dependent variable and the changes in each individual psychometric trait constituted the independent variables. The results, as shown in Table 7, are statistically significant $\mathrm{F}(1,56)=0.159(p=$ $0.004)$; however, the regression equation only accounts for $14.1 \%$ of the variability in the data. The only statistically significant variable is change in agreeableness ( $\Delta$ Agreeableness) and the data indicates that as agreeableness increases, the predicted performance (EXAM AVG) decreases. Persons with high scores on agreeableness forgive the wrongs that they have suffered, are lenient in judging others, are willing to compromise and cooperate with others, and can easily control their temper (http://hexaco.org/scaledescriptions). We interpret this result to imply that team members who refuse to 
speak up and contribute to team effort, but went along with the flow, so to speak, did not benefit from the learning that is associated with true discourse and hence did not perform well on the exam. Thus, H4 is partially supported in that only the change in agreeableness are unique and significant predictors of individual performance. None of the other psychometric changes had a statistically significant impact on individual performance.

TABLE 7

CHANGE IN INDIVIDUAL PSYCHOMETRICS AND PERFORMANCE

\begin{tabular}{|c|l|r|r|r|r|r|}
\hline & \multicolumn{5}{|c|}{ Step 1 } & \\
\hline Model & & B & Std. err. & $\boldsymbol{\beta}$ & t & \multicolumn{1}{c|}{$\boldsymbol{p}$} \\
\hline 1 & AAgreeableness & -14.98 & 4.95 & -0.38 & -3.03 & 0.004 \\
\hline & $\mathrm{r}$ & & 0.375 & & & \\
\hline & $\mathrm{r}^{2}$ & & 0.141 & & \\
& F & 9.159 & & 0.004 \\
& df-regression & 1 & & \\
& df-residual & 56 & & \\
\hline & Dependent Variable: EXAM AVG & & & & \\
\hline
\end{tabular}

Testing H5 - Intense Virtual Teamwork Induces Significant Changes in Team Personality Traits

We defined group psychometrics as the average of the group member psychometrics (Shalwany et al., 2018; 2019). Per course guidelines, students can collaborate to prepare for daily quizzes and weekly exams. However, quizzes and exams are individual, so that while students can use collaboration to learn the material, they must demonstrate competency individually.

As with individual psychometrics, team psychometrics also change from the beginning of the course to the end. Table 8 illustrates the results of a one sample t-test for the equality of means and the nonparametric one-sample Wilcoxon's Signed Rank test for equality of medians. The latter test is included because we are not able to ascertain whether the assumptions for the parametric $t$ test are satisfied. The results indicate that groups collectively change psychometrics mirroring the individual changes. The major difference is that extraversion did not change in groups like it did for individuals. However, openness to experience does increase, while altruism decreases. The emotional intelligence quadrant of self-awareness does decrease significantly between the beginning and the end of the course. Selfawareness of a team is expressed by "team members having empathy for each other, and there are norms to support vigilance and mutual understanding" (Goleman et al., 2002). Having the HEXACO-PI-R domain of altruism decrease appears to be consistent with a decrease in the quadrant of self-awareness. They both refer to a reservoir of goodwill that may exist in a team. However, as the team continues its intense collaborative efforts to meet its goals, the tolerance and goodwill toward individuals that are not doing their part is likely to decrease.

Based on the above results, the data partially support H5: Short term intense team collaboration appears to significantly change the domains of openness to experience and altruism. It also appears to change the emotional intelligence quadrant of self-management. 
TABLE 8

CHANGES IN GROUP PSYCHOMETRICS

\begin{tabular}{|c|c|c|}
\hline \multirow[t]{2}{*}{ HEXACO-PI-R DOMAIN LEVEL SCORES } & One Sample & Wilcoxon's \\
\hline & t-test & Signed Rank Test \\
\hline DOMAIN & Significant $(p)$ & Significant $(p)$ \\
\hline$\Delta$ Honesty - Humility & no & no \\
\hline$\Delta$ Emotionality & no & no \\
\hline$\Delta$ Extraversion & no & no \\
\hline$\Delta$ Agreeableness & no & no \\
\hline$\Delta$ Conscientiousness & no & no \\
\hline$\Delta$ Openess to Experience & yes $(0.021)$ & yes (0.023) \\
\hline$\Delta$ Altruism & yes $(0.046)$ & no $(0.058)$ \\
\hline \multicolumn{3}{|c|}{ GLOBAL EMOTIONAL INTELLIGENCE SCORES } \\
\hline \multicolumn{3}{|l|}{ QUADRANT } \\
\hline$\Delta$ Self-Awareness & no $(0.057)$ & yes $(0.042)$ \\
\hline$\Delta$ Self-Management & no & no \\
\hline$\Delta$ Social Awareness & bo & bo \\
\hline$\Delta$ Relationship Management & no & no \\
\hline$\triangle$ LOCUS OF CONTROL & & no \\
\hline $\mathrm{N}$ & 13 & 13 \\
\hline
\end{tabular}

Testing H6 - Induced Changes in Team Personality Traits Are Significant Predictors of Team Performance

The preceding discussion identifies significant changes in team psychometrics. In order to determine if these changes had an impact on team performance, we conduct a stepwise multiple regression with the average group grades in the course as the dependent variable and the changes in each of the group psychometrics as the independent variable. Table 9 exhibits the results.

TABLE 9

STEPWISE MULTIPLE REGRESSION RESULTS OF PSYCHOMETRICS AND PERFORMANCE

\begin{tabular}{|c|c|c|c|c|c|c|c|c|c|c|c|}
\hline & & & & Step 1 & & & & & Step 3 & & \\
\hline Model & & B & Std. err. & $\beta$ & $\mathrm{t}$ & $p$ & B & Std. err. & $\beta$ & $\mathrm{t}$ & $p$ \\
\hline 1 & $\Delta$ Relationship Management & 3.81 & 1.265 & 0.604 & 2.517 & 0.029 & 0.466 & 1.322 & 0.739 & 3.52 & 0.006 \\
\hline 2 & $\Delta$ Self-Awareness & & & & & & -8.099 & 3.434 & -0.495 & -2.358 & 0.04 \\
\hline & $r$ & & 0.604 & & & & & 0.77 & & & \\
\hline & $r^{2}$ & & 0.365 & & & & & 0.592 & & & \\
\hline & $F$ & & 6.334 & & & 0.029 & & 7.261 & & & 0.011 \\
\hline & df-regression & & 1 & & & & & 2 & & & \\
\hline & df-residual & & 11 & & & & & 10 & & & \\
\hline & \multicolumn{2}{|c|}{ Dependent Variable: EXAM 4 AVG } & & & & & & & & & \\
\hline
\end{tabular}


The $\mathrm{r}^{2}$ of 0.592 indicates a good fit, while $\mathrm{F}(2,10)$ has $p=0.011$ is significant. The results indicate that as relationship management increases, performance increases. On the other hand, as self-awareness increases, performance decreases. This implies that while being sympathetic and understanding of team members at the beginning of a project may be good, over the duration of a project, such empathy and understanding can backfire and lead to poor individual performance to the detriment of all team members. Thus, H6 is partially supported. The change in the HEXACO-PI-R domain of self-awareness and the emotional intelligence Quadrant of Self Awareness do impact team performance. None of the other psychometrics do.

\section{DISCUSSION}

In this study, we examine the impact of short-term, intense, virtual team collaboration on the psychometric characteristics of individual team members and of entire teams. We also investigate the corresponding impact on individual and team performance.

For individual team members, our results indicate that the personality, emotional intelligence, and locus of control for a large majority of individuals changed. There is a high statistically significant correlation between the psychometrics at the beginning of the course and at the end of the course. Thus, the changes in psychometrics that occur between the start and end of the course are predictable. In every instance, individuals with high psychometric measures at the beginning of the course exhibit lower scores at the end of the course. Conversely, individuals with low psychometric scores at the beginning of the course present higher scores at the end of the course. These findings imply that psychometrics are malleable and that short-term, intense, virtual collaboration forces individual team members to adapt their psychometrics to seek a balance that is appropriate to the demands of the team. Teams in which this balance is achieved seem to achieve something akin to what Csickzentmihalyi (1997) refers to as "flow," the experience in which every individual in the team is performing at the best of their ability as a member of the team. It also seems to correspond to teams reaching the stage of "performing" in Tuckman's (1965) stages of group development.

Crossover points - the point at which the predicted end psychometric measure changes from being lower than the actual beginning score to being higher-are identified for every psychometric construct. This finding extends the work of Curseu, Llies, Virga, Maricutoiu, and Sava (2018), who report that the personality traits of extraversion, agreeableness and conscientiousness of Goldberg's (1990) "Big Five" model have inverted U-shaped relationships with contributions to teamwork. Their definition of inverted U-shaped relationship corresponds to our notion of the crossover point, which is the inflection point of the inverted U shape. Furthermore, while they attribute their findings to contribution to teamwork, our result suggests that it is teamwork that is the cause, not the effect of this change in LOC.

Of the psychometric movements, we see a statistically significant increase in HEXACO-PI-R domain level scores in extraversion, and openness to experience, as well as a decrease in altruism. A qualitative analysis of student reflections about their course experience indicate that the daily quizzes and short deadlines push students past the boundaries of collaboration they experience in other courses. They describe previous group work as consisting of divvying up project tasks among group members at the beginning of the semester and putting the individual results together into a final report at the end of the semester. In contrast, they feel that in this course, they truly must interact with each other because they realize that the more brains working on the same problem, the better and that it is helpful to hear each other's outlook on the problem. Similar enlightenment should occur when teams are assigned to organizational projects. Qualitative, end-of-semester comments indicate that the intense collaborative experiences placed on individuals by the process force individuals to come out of their shell, listen to other team member opinions, find the "happy medium," or collective "flow" with their team members.

The decrease in altruism is explained by several groups indicating that they had a member who would seldom contribute ideas when asked by others, but constantly sent out messages asking for help when deadlines were looming. In such cases, it became standard team procedure that if a member did not contribute, the member did not receive help. 
Further, we conjecture that the increase in extraversion and openness to experience can be attributed, at least partially, to students learning to be more vocal and to verbally express themselves so that the team can reach its overarching objectives. On the other hand, participants in this study saw a decrease in agreeableness. As noted earlier, individuals with high scores on agreeableness forgive the wrongs that they have suffered and are lenient in judging others (http://hexaco.org/scaledescriptions). We interpret this result to be complementary to the statistically significant change in openness to experience. As collaboration progresses and team members begin to see the value in hearing each other's points of view, they will be less likely to simply go with the flow but, instead, will want to argue the merits of each other's points of view. Those that simply accept other points of view in order to be agreeable will not learn from the collaborative experience. Being agreeable may be good in terms of getting along with teammates, but it can lead to poor performance (the pied piper syndrome), as evidenced by the findings in this study. This result applied to all team members regardless of gender. Moreover, this conjecture regarding agreeableness is supported by Juhász (2005, 2010) and Barrick and Mount (1993), who found that agreeableness negatively affects team performance.

A similar explanation can be proposed for a significant decrease in the emotional intelligence quadrant of self-awareness. Self-awareness involves empathy for others (Goleman et al., 2002) and team members may eventually run short of empathy and instead decide to hold team members accountable. In support of this speculation, increases in team self-awareness are also found to decrease team performance, while increases in team relationship management result in an increase in team performance.

All teams are subject to intense short-term team collaboration in the course. The purpose is to meet their individual and collective goals of achieving a high grade in the course. However, except for agreeableness, which is negatively related to performance, we find that changes in psychometric traits have no significant effect on individual performance. Similar findings are revealed regarding changes in PT, LOC, and EI on team performance. For the most part, the various domains are non-significant. However, team performance is positively correlated with relationship management $(\mathrm{B}=0.46)$, indicating that those that can extract team member performance from their teams through their relationship skills can improve the team grade $(B=0.46)$. However, self-awareness is likely to result in a decrease in team performance $(\mathrm{B}=-8.099)$. The regression model exhibiting those results has an $\mathrm{r}^{2}$ of 0.592 .

\section{CONCLUSIONS}

A team structure now dominates the way in which work is completed in organizations (Deloitte, 2016; Hoch, 2014). The predominance of teams has encouraged some practitioners and academicians to encourage team formation based on personality traits (e.g., Akmal, 2015; Allen \& Woodley, 2016; Harper, 2018; Shalwani et al., 2018; Shalwani et al., 2019). Indeed, the literature abounds with studies that seek to identify which mix of personality traits in a team will enhance team performance, either on their own merit, or through building team cohesion, which is associated with team performance (Aeron \& Pathak, 2012; Akmal, 2015; Allen \& Woodley, 2016; Juhasz, 2010; van Vianen \& De Dreu, 2001). However, the major takeaway from this empirical research is that it may be fruitless for managers and/or HR departments to focus on finding the right mix of personalities to include in a team. Our results suggest that team member psychometrics are malleable and offer support to a small body of prior work (e.g., Lucas and Donnellan 2011; Specht et al. 2011). Our findings also indicate that approximately half of the team members who engage in intense collaboration throughout the course will alter their personalities, so as to best accomplish the team objectives. This finding offers support of Bandura's Efficacy Theory (Bandura, 1977).

Findings in this study also reveal that individuals at the endpoints of the psychometric scales at the beginning of the collaboration process moderate these traits as the collaboration progresses. Participants may revise certain traits toward the middle of the scales because they consciously or unconsciously recognize that achieving team goals requires individual personality changes. Organizational team members should undergo similar psychometric trait moderation. 
Decreases in altruism, self-awareness, and agreeableness are noted. While typically such traits would be considered desirable in teammates, this research corroborates other studies which reveal that these traits can reduce team effectiveness (Barrick and Mount, 1993; Juhász, 2005, 2010). These findings should be of particular interest to managers responsible for team formation who may in the past have sought to place individuals who score very high on these traits on teams in the interest of reducing conflict. Conversely, increases in extraversion and openness to experience are noted as positive changes to team member personalities. These traits encourage team members to seek team cohesiveness, but to balance it by speaking their minds and debating the wisdom of adopting certain paths proposed by other team members.

\section{LIMITATIONS AND FUTURE RESEARCH}

This study utilizes MBA students as participants, which may be a limitation and restrict the generalization of these findings. While most of the study participants are both full-time employees and part-time students, efforts should be made to replicate this study within a corporate environment as the role of student or the classroom environment may bias the findings. In addition, perhaps general industry cultures may affect the degree to which individual psychometric traits change. Thus, comparing the malleability of personalities across industries is another avenue for research.

Employees and students who exert the effort to perform well within a team are generally rewarded. Employees continue to be employed, receive a paycheck, and perhaps, are awarded a promotion. Students receive good grades, maintain scholarships, and perhaps, receive better job offers in the future. However, do similar personality changes occur when there is no reward for team effectiveness? Future research might investigate whether intensive teamwork alone is enough to generate psychometric changes.

Another avenue for research is to determine the longevity of psychometric changes that are the result of short-term, intensive team collaborations. Will the individual changes extend beyond that teamwork or will the individual immediately revert to prior behaviors?

\section{REFERENCES}

Aeron, S., \& Pathak, S. (2012). Relationship between team member personality and team cohesion. Management and Labour Studies, 37(3), 267-282.

Akila, R., \& Thangavel, N. (2013). Impact of team leaders' emotional intelligence competence on teams' emotional intelligence. International Journal on Leadership, 1(1), 7-12.

Akmal, K. (2015). Personality traits influence on team cohesion and performance: The moderating effect on leadership. Information and Knowledge Management, 5(4), 104-109.

Allen, N. J., \& Hecht, T. D. (2004). The 'romance of teams': Toward an understanding of its psychological underpinnings and implications. Journal of Occupational and Organizational Psychology, 77(4), 439-461.

Allen, N., \& Woodley, H. (2016). Personality and teamwork. In V. Zeigler-Hill, T.K. Shackelford (eds.), Encyclopedia of Personality and Individual Differences. Switzerland: Springer AG.

Ashforth, B. E., Harrison, S. H., \& Corley, K. G. (2008). Identification in organizations: An examination of four fundamental questions. Journal of Management, 34(3), 325-374.

Ashton, M. C., \& Lee, K. (2009). The HEXACO-60: A short measure of the major dimensions of personality. Journal of Personality Assessment, 91, 340-345.

Ashton, M. C., Lee, K., \& Goldberg, L. R. (2004). A hierarchical analysis of 1,710 English personalitydescriptive adjectives. Journal of Personality and Social Psychology, 87(5), 707- 721.

Bandura, A. (1977). Self-efficacy: The exercise of control. New York: W.H. Freeman.

Barrick, M., \& Mount, M. (1993). Autonomy as a moderator of the relationship between the big five personality dimensions and job performance. Journal of Applied Psychology, 78(1), 111- 118.

Bleidorn, W. (2012). Hitting the road to adulthood: Short-term personality development during a major life transition. Personality and Social Psychology Bulletin, 38, $1594-1608$. 
Boone, C., Van Olfen, R., \& Witteloostuijn, A. (2005). Team locus of control composition, leadership structure, information acquisition, and financial performance: A business simulation study. Academy of Management Journal, 48(5), 889-909.

Bowes, S. M., Watts, A. L., Thompson, W. W., \& Lilienfeld, S. O. (2019). Clarifying the association between psychopathy dimension and internalizing symptoms in two community samples: The role of general personality. Personality and Individual Differences, 147, 144-155.

Carson, J. B., Tesluk, P. E., \& Marrone, J. A. (2007). Shared leadership in teams: An investigation of antecedent conditions and performance. Academy of Management Journal, 50, 1217-1234.

Chemiss, C., \& Adler, M. (2000). Promoting emotional intelligence in organizations: Making training in emotional intelligence effective. Alexandria, VA: Association for Talent Development.

Clarke, N. (2010). Developing emotional intelligence abilities through team-based learning. Human Resource Development Quarterly, 21(2), 119-138.

Codier, E., Freitas, B., \& Muneno, L. (2013). Developing emotional intelligence ability in oncology nurses: A clinical rounds approach. Oncology Nursing Forum, 40(1), 22-29.

Coetzer, G. H. (2015). Emotional versus cognitive intelligence: Which is the better predictor of efficacy for working in teams? Journal of Behavioral and Applied Management, 16(2), 116- 133.

Costa, P. T., Jr., Terracciano, A., \& McCrae, R. R. (2001). Gender differences in personality traits across cultures: Robust and surprising findings. Journal of Personality and Social Psychology, 81(2), 322-331.

Csickszentmihalyi, M. (2007). Living Well: The Psychology of Everyday Life. London: Weidenhelm and Nicholson.

CultureWizard. (2018). 2018 trends in high-performing global virtual teams. Retrieved from https://www.rw-3.com/blog/trends-in-global-virtual-teams.

Curseu, P., Llies, R., Virga, D., Maricutoiu, L., \& Sava, F. (2018). Personality characteristics that are valued in teams: Not always "more is better." International Journal of Psychology, 1-12.

Deci, E. L., \& Ryan, R. M. (1985). Intrinsic motivation and self-determination in human behaviour. New York: Plenum.

Deci, E. L., \& Ryan, R. M. (2000). The 'what' and 'why' of goal pursuits: Human needs and the self determination of behaviour. Psychological Inquiry, 4, 227-268.

Delarue, A., Van Hootegem, G., Procter, S., \& Burridge, M. (2008). Teamworking and organizational performance: A review of survey-based research. International Journal of Management Reviews, 10(2), 127-48.

Deloitte U.S. (2016). Global Human Capital Trends. Retrieved from https://www2.deloitte.com/us/en/insights/focus/human-capital-trends.html.

Demir, S., Demir, S. G., Bulut, H., \& Hisar, F. (2014). Effect of mentoring program on ways of coping with stress and locus of control for nursing students. Asian Nursing Research, 8(4), 254-260.

Dhani, P., \& Sharma, T. (2016). Relationship between emotional intelligence and job performance. New Dimensions for Dynamic Business Practices. Mumbai: Shroff Publishers \& Distributors Pvt. Ltd., 289-291.

Dhani, P., \& Sharma T. (2017). Effect of emotional intelligence on job performance of IT employees: A gender study. Procedia Computer Science, 122, 180-185.

Frye, C. M., Bennett, R., \& Caldwell, S. (2006). Team emotional intelligence and team interpersonal process effectiveness. Mid-American Journal of Business, 21(1), 49-56.

Gilson, L. L., Maynard, M. T., Young, N. C. J., Vartiainen, M., \& Hakonen, M. (2014). Virtual teams research 10 years, 10 themes, and 10 opportunities. Journal of Management, 41(5), 1313 1337.

Glassop, L. I. (2002). The organizational benefit of teams. Human Relations, 55(2), 225-249.

Gochenaur, R. I. (2010). Wilderness leadership training courses influence on self-perception and locus of control (Order No. 1484296). Available from ProQuest Dissertations \& Theses Global. (847373045). 
Goldberg, L. R. (1990). An alternative "description of personality": The big-five factor structure. Journal of Personality and Social Psychology, 59, 1216-1229.

Greenberg, P.S., Greenberg, R.H., \& Antonucci, Y.L. (2007). Creating and sustaining trust in virtual teams. Business Horizons, 50(4), 325-333.

Guchait, P., Hamilton, K., \& Hua, N. (2014). Personality predictors of team taskwork understanding and transactive memory systems in service management teams. International Journal of Contemporary Hospitality Management, 26(3), 401-425.

Günüşen, N., Serçekus, P., \& Edeer, A. (2014). A comparison of problem-based and traditional education on nursing students' locus of control and problem-solving skills. International Journal of Nursing Knowledge, 25(2), 110-115.

Harper, H. (2018). How to use the science of personality when building an effective team. Retrieved from https://www.workstyle.io/can-i-build-a-more-effective-team-based-on-personality.

Hess, J. D., \& Bacigalupo, A. C. (2011). Enhancing decisions and decision-making processes through the application of emotional intelligence skills. Management Decision, 49(5), 710-721.

Hoch, J. E. (2014). Shared leadership, diversity, and information sharing in teams. Journal of Managerial Psychology, 29(5), 541-564.

Hounkpatin, H., Wood, A., Boyce, C., \& Dunn, G. (2015). An existential-humanistic view of personality change: Co-occurring changes with psychological well-being in a 10-year cohort study. Social Indicators Research, 121(2), 455-470. doi:10.1007/s11205-014-0648-0

Huszczo, G., \& Endres, M. L. (2017). Gender differences in the importance of personality traits in predicting leadership self-efficacy. International Journal of Training \& Development, 21(4), 304317. doi:10.1111/ijtd.12113

Jackson, J. J., Thoemmes, F., Jonkmann, K., Lüdtke, O., \& Trautwein, U. (2012). Military training and personality trait development: Does the military make the man, or does the man make the military? Psychological Science, 23, $270-277$.

Joseph, D., Jin, J., Newman, D., \& O’Boyle, E. (2014). Why does self-reported emotional intelligence predict job performance? A meta-analytic investigation of mixed EI. Journal of Applied Psychology, 100(2), 298-342.

Joseph, D. L., \& Newman, D. A. (2010). Emotional intelligence: An integrative meta-analysis and cascading model. Journal of Applied Psychology, 95, 54-78.

Juhász, M. (2005). Influence of criterion change on supervisory rating concerning the five-factor model. Periodica Polytechnica Social and Management Sciences, 13(1), 45-59.

Juhász, M. (2010). Influence of personality on teamwork behavior and communication. Social and Management Sciences, 18(2), 63-77.

Kaifi, B. A., \& Noori, S. A. (2010). Organizational management: A study on middle managers, gender, and emotional intelligence levels. Journal of Business Studies Quarterly, 1(3), 13-23.

Kaufman, S. B., Yaden, D. B., Hyde, E., \& Tsukayama, E. (2019). The light vs. dark triad of personality: Contrasting two very different profiles of human nature. Frontier in Psychology, 10, 1-26.

Koman, E. S., \& Wolff, S. B. (2008). Emotional intelligence competencies in the team and team leader: A multi-level examination of the impact of emotional intelligence on team performance. The Journal of Management Development, 27(1), 55-75.

Laher, S., \& Croxford, S. (2013). Men are from Mars; women are from Venus: Exploring gender differences in personality in the South African context. SA Journal of Human Resource Management, 11(1), 1-8.

Lee, K., \& Ashton, M. C. (2004). Psychometric properties of the HEXACO personality inventory. Multivariate Behavioral Research, 39, 329-358.

Lucas, R. E., \& Donnellan, M. B. (2011). Personality development across the life span: Longitudinal analyses with a national sample from Germany. Journal of Personality and Social Psychology, $101,847-861$.

Martin, L. S. (2013). Intentional personality change: preliminary evaluation of a coaching intervention. Doctor of Philosophy thesis, Sydney Business School, University of Wollongong. 
Motamedi, F., Ghobari-Bonab, B., Beh-pajooh, A., Yekta, M. S., \& Afrooz, G. A. (2017). Developing an emotional intelligence program training and study its effectiveness on emotional intelligence of adolescents with emotional and behavioral problems that living in single parent families. Journal of Education and Learning, 6(2), 101-110.

Nowicki, S. (2016). Choice or chance: Understanding your locus of control and why it matters. Amherst, NY: Prometheus Books.

O'Boyle, E. H., Humphrey, R. H., Pollack, J. M., Hawver, T. H., \& Story, P. A. (2011). The relation between emotional intelligence and job performance: A meta-analysis. Journal of Organizational Behavior, 32, 788-818.

Orak, R. J., Farahani, M. A., Kelishami, F. G., Seyedfatemi, N., Banihashemi, S., \& Havaei, F. (2016). Investigating the effect of emotional intelligence education on baccalaureate nursing students' emotional intelligence scores. Nurse Education in Practice, 20, 64-69.

Ottley, A., Crouser, R. J., Ziemkiewicz, C., \& Chang, R. (2012). Priming locus of control to affect performance. 2012 IEEE Conference on Visual Analytics Science and Technology (VAST), (October).

Roberge, M., \& Huang, W. (2019). A conceptual model of individual and collective personality in motion. Journal of Organizational Psychology, 19(2), 131-143.

Roberts, B., \& Wood, D. (2006). Personality development in the context of the neo-socioanalytic model of personality. In D. Mroczek \& T. Little (Eds.), Handbook of Personality Development (pp. 1139). Mahwah, NJ: Lawrence Erlbaum Associates Publishers.

Roberts, B., Wood, D., \& Smith, J. (2005). Evaluating five factor theory and social investment perspectives on personality trait development. Journal of Research in Personality, 39, 166-184.

Rotter, J. B. (1954). Social learning and clinical psychology. Englewood Cliffs: NJ Prentice-Hall.

Rotter, J. B. (1966). Generalized expectancies for internal versus external control of reinforcement. Psychological Monographs: General \& Applied, 80(1), 1-28.

Semykina, A., \& Linz, S. J. (2010). Analyzing the gender pay gap in transition economies: How much does personality matter? Human Relations, 63(4), 447-469.

Shalwani, A., Line, B., Delvinne, H., Saseendras, A., \& Sullivan, K. (2019). Team structuring based on personality and emotionality traits for better project performance. $55^{\text {th }}$ ASC Annual International Conference, Minneapolis, MN.

Shalwani, A., Smithwick, J., Hurtado, K., \& Sullivan, K. (2018). Relationship of construction engineering and management student performance with personality traits: HEXACO and emotional intelligence. $54^{\text {th }}$ ASC Annual International Conference, Denver, CO.

Specht, J., Egloff, B., \& Schmukle, S. (2011). Stability and change of personality across the life course: The impact of age and major life events on mean-level and rank-order stability of the big five. Journal of Personality and Social Psychology, 101, 862-882.

Stover, S. H. (1988). An investigation of locus of control and its relationship to leadership training (Order No. 8901978). Available from ProQuest Dissertations \& Theses Global: Social Sciences (303722464).

Tuckman, B. (1965). Development sequence in small group. Psychological Bulletin, 63(6), 384-399.

Swart, W., \& Wuensch, K. (2016). Flipping quantitative classes: A triple win. Decision Sciences Journal of Innovative Education, 14(1), 67 - 89.

Swart, W., O’Dor, R., Siguaw, J., \& Karriker, J. (2019). Contextualized leadership development:The concurrent enhancement of leadership qualities and subject matter expertise. International Leadership Journal, 11(3), 3-34.

Tasa, K., Sears, G., \& Schat, A. (2011). Personality and teamwork behavior in context: The cross-level moderating role of collective efficacy. Journal of Organizational Behavior, 32(1), 65-85.

Tasselli, S., Kilduff, M., \& Landis, B. (2018). Personality change: Implications for organizational behavior. Academy of Management Annals, 12, 467-493.

Tupes, E. C., \& Christal, R. E. (1961). Recurrent personality factors based on trait ratings. USAF ASD Tech. Rep. (61-97). Retrieved from https://www.scirp.org/. 
Ulutas, I., \& Ömeroglu, E. (2007). The effects of an emotional intelligence education program on the emotional intelligence of children. Social Behavior and Personality, 35(10), 1365-1372.

van Vianen, A., \& De Dreu, C. (2001). Personality in teams: Its relationship to social cohesion, task cohesion, and team performance. European Journal of Work and Organizational Psychology, 10(2), 97-120.

Vasilatos, O. R. (2010). Team personality composition and team effectiveness in the virtual context: The role of degree of virtualness and time (Order No. 3421910). Available from ProQuest Dissertations \& Theses Global (756463637).

Waldman, D., Balthazard, P., \& Peterson, S. (2011). Leadership and neuroscience: Can we revolutionize the way that inspirational leaders are identified and developed? Academy of Management Perspectives, 25(1), 60-74.

Wang, M., \& Hsu, B. (2012). A study to explore the team virtualization level and team effectiveness from the team personality composition. Journal of the Knowledge Economy, 3(2), 199-216.

Weissbein, D., Huang, J., Ford, K., \& Schmidt, A. (2011). Influencing learning states to enhance trainee motivation and improve training transfer. Journal of Business and Psychology, 26(4), 423-435.

Yu-Wei, L., \& Linz, S. (2017). Gender gap in upward mobility: What is the role of non-cognitive traits? International Journal of Manpower, 38(6), 835-853.

Zimmermann, J., \& Neyer, F. J. (2013). Do we become a different person when hitting the road? Personality development of sojourners. Journal of Personality and Social Psychology, 105, 515530.

Zuofa, T., \& Ochieng, E. G. (2017). Working separately but together: Appraising virtual project team challenges. Team Performance Management, 23(5), 227-242. 